\title{
Associations of marital and parental status and family members living together with health-related behaviors in Japanese young workers : a cross-sectional study
}

\author{
Mariko Nakamoto*, Yukiko Tanaka, Satomi Ono, Akiko Nakamoto, Emi Shuto, and Tohru Sakai \\ Department of Public Health and Applied Nutrition, Institute of Biomedical Sciences, Tokushima University Graduate School, Tokushima, Japan
}

\begin{abstract}
The aim of this study was to clarify the associations of family members living together with healthrelated behaviors in Japanese young workers. The participants were 300 men and women aged 20-39 years in 2015 who had a job. A web-based self-administered questionnaire on status of partnering and parenting, number of family members living together, dietary habits, drinking habit, smoking habit, self-rated health, employment status, working time and commuting time was conducted through Internet. Multiple logistic regression analysis and general linear models were used to assess the association of family members living together with healthrelated behaviors. The multivariate-adjusted odds ratio ( $95 \%$ confidence interval, $p$-value) for current drinking in unmarried participants living with their parents compared to unmarried participants living alone was 0.35 $(0.13-0.93, p=0.036)$. The adjusted means of frequency of breakfast skipping and frequency of eating out showed a trend for inverse associations with the presence of a partner and children. However, those associations disappeared after adjustment for age of youngest child. The findings suggest that the presence of parents might affect drinking behavior and that age of youngest child living together might affect the frequency of breakfast skipping in young Japanese workers. J. Med. Invest. 66 : 141-147, February, 2019
\end{abstract}

Keywords : marital status, parental status, health-related behaviors, young Japanese worker, cross-sectional study

\section{INTRODUCTION}

In the past several decades, the rates of partnering (becoming married and/or living as married) and parenting have been decreasing in Japan (1) and the decreasing rates have become a social problem. Vital statistics obtained by the Ministry of Health, Labour and Welfare in Japan have shown that the average ages of mothers at the birth of the first child were 25.7 years in $1975,27.5$ years in 1995 and 30.7 years in 2015 (2). The average age of mothers at the birth of their children is estimated to continue to increase in Japan (2). Partnering and/or parenting are important life-stage changes that commonly occur during young adulthood such as 20-40 years of age.

Life-stage changes such as partnering and/or parenting are often associated with changes of lifestyle and/or behavior such as the use of time, social norms, social support, income, smoking and drinking habits, dietary behavior and expectations of others (3-8). The household environment and social environment have been reported to affect health-promoting behaviors such as a healthy diet and physical activity in western populations (9-11). In a crosssectional study, a positive association of partnering and better dietary eating (e.g., intake of more fruit and vegetables) was shown in Australian men (12). In addition, it was shown that people who were single or had no children were more likely to skip breakfast and consume fast foods than those who were married or had children $(13,14)$. On the other hand, it was reported that partnered women have worse dietary eating (e.g., intake of more

Received for publication October 31, 2018; accepted December 22, 2018.

Address correspondence and reprint requests to Mariko Nakamoto, MSc, PhD, Department of Public Health and Applied Nutrition, Institute of Biomedical Sciences, Tokushima University Graduate School, 3-18-15, Kuramoto-cho, Tokushima city, Tokushima 770-8503, Japanand Fax +81 886-33-9427. fat and sugar) than single women (12). Incoherent associations between partnering and/or parenting and dietary habits have also been shown in several prospective studies (15-19). In Japan, a few studies showed an association between partnering and/or parenting and dietary skipping $(20,21)$, though there is a possibility of differences in concepts about partnering and/or parenting from those in western countries.

The associations of marital and parental status and family members living together (e.g., unmarried and alone, unmarried and living with parents, married and living with a partner, and married and living with both a partner and children) with health-related habits including self-rated behavior, smoking habit, drinking habit, skipping breakfast, eating out and dietary variety have not been elucidated. Therefore, we analyzed the associations of marital and parental status and family members living together with the above six health-related habits in Japanese workers aged 20-40 years.

\section{PATIENTS AND METHODS / \\ MATERIALS AND METHODS \\ Study population}

We conducted an Internet panel survey that included participants already registered with an Internet survey company (Marsh Co., Ltd.). This internet panel survey was conducted between August 28, 2015 and September 2, 2015 for Internet users aged 20-49 years in Tokushima Prefecture, Japan. For survey participants registered in advance, questionnaires and a response column were displayed on the website for the respondents to complete and transmit their responses. A total of 300 people who had registered with the survey company took part in the present study. The participants were extracted on the basis of the population composi- 
tion ratios for residential areas so as to make a male/female ratio of $1: 1$. Participants were those who completed the survey. All of the people who were registered with the survey company had been registered by open recruitment. In August 2015, the total number of monitors was about 800,000 , and the total number of monitors in Tokushima Prefecture was about 4000 . As a countermeasure against incorrect answers, at the time of registration, the system check was performed to prevent duplicate registration and registration inconsistency points based on some registration information as well as mandatory update of monitor registration information once a year. The study protocol was approved by the institutional review board of Tokushima University Hospital (Ethical approval number: 2335).

\section{Assessment of health-related behaviors}

We assessed six variables (self-rated health, smoking habit, drinking habit, skipping breakfast, takeaway-food consumption and dietary diversity) during the last year as health-related behaviors with the following questions. Self-rated health was assessed by the question "How do you feel about your health status?" We defined participants who answered 'very good' or 'reasonably good' for this question as participants with good self-rated health. We defined participants who answered 'very bad' or 'reasonably bad' for this question as participants with bad self-rated health. Smoking habit was assessed by the question "Do you smoke?" We defined participants who answered 'every day' and 'sometimes' for this question as a current smokers. We defined participants who answered 'in the past' and 'never' for this question as not current smokers. The participants were asked how often they take alcohol and five response options were given : never or almost never, once a week, 2 or 3 times a week, 4 or 5 times a week, and every day. To analyze drinking behavior, nondrinkers were categorized as those who responded never or almost never, and current drinkers were categorized as those with a drinking frequency of more than one time a week. Weekly breakfast skipping was estimated using the question "How many times per week do you usually skip breakfast?". All of the participants answered the number of times they skip breakfast in one week. Weekly takeaway-food consumption was estimated using the question "How many times per week do you usually eat takeaway food?". All of the participants answered the number of times they eat takeaway food in one week. Dietary variety was calculated using the method reported by Kumagai $e t$ al (22). For assessing dietary variety, we used a dietary variety score for 10 food groups consumed daily from food frequency questionnaires : fish and shellfish, meats, eggs, milk and dairy products, beans, green/yellow vegetables, seaweed, potatoes, fruits, and fat and oil. If participants selected 'almost every day' as the frequency of each food group intake, the score for that food group was one point. Therefore, the dietary variety score ranged from 0 to 10 with a higher score indicating a higher dietary variety.

Marital and parental status and family members living together

The participants were asked to report their marital status (single, married or separated/divorced). Regarding parental status, the participants were asked to report how many biological children they had and the age for each child. Regarding family members living together, the participants were asked to report their family members including their father, mother, grandfather, grandmother, brother/sister, children, and others. The number of separated/divorced participants was very small $(n=13)$. In addition, almost of all of the unmarried participants living with someone reported that they live with their parents $(90.6 \%)$. The participants were classified into four groups of marital and parental status: 'Single and unmarried (including separated/divorced) and living with a person other than their parents', 'unmarried (including separated/divorced) and living with parents', 'married without children' and 'married with children'.

\section{Covariates}

The participants were requested to provide information on all of the following variables: age, gender (binary : man or woman), employment status (categorical : regular employment, part time or other), working time (hours), and commuting time (hours).

\section{Statistical analysis}

At first, comparisons of the basic characteristics of participants according to marital and parental status and family members living together were performed. Continuous variables were expressed as means \pm standard deviation, and simple comparisons of the means of data were performed using analysis of variance. Categorical variables were expressed as numbers (percentages), and comparisons of proportions were performed using the chi-square test.

Next, multiple logistic regression analysis was used to estimate the odds ratios (OR) and 95\% confidence intervals (CI) for healthrelated behaviors including bad self-rated health, current smoking and regular drinking according to marital and parental status and family members living together after controlling potential confounders. Single and unmarried participants living with a person other than their parents were defined as references in the present analysis. General linear models were used to estimate the adjusted means of frequency of weekly breakfast skipping and eating out and score of dietary variety according to marital and parental status and family members living together after controlling for potential confounders. When we used those analyses to assess the association between the six health-related behaviors and marital and parental status and family members living together, we controlled the following variables as potential confounders. The confounding variables were 1) Model 1, age (continuous) and sex (binary : man or woman) ; 2) Model 2, Model 1 + employment status (categorical : regular employment, part time or other) and working time (continuous) ; and 3) Model 3, Model $2+$ age of youngest child (as continuous:no child, 0-4 years, 5-9 years, 10-14 years, $15-19$ years, $\geq 20$ years).

All statistical tests were based on two-sided probabilities and were performed using SPSS version 18.0J for Windows (SPSS Inc., Japan, Tokyo Japan). All $p$ values $<0.05$ were considered statistically significant.

\section{RESULTS}

\section{Characteristics of study participants}

The total number of subjects was 300 (150 men and 150 women). The mean ages were $40.2 \pm 6.8$ years in men and $38.3 \pm 6.3$ years in women.

Table 1 shows the characteristics of participants according to marital and parental status and family members living together. The number of participants living with a person other than their parents or living alone was $41(13.7 \%)$. The number of participants living with their parents was 58 (19.3\%). Among the married participants, $42(14.0 \%)$ had no children and $159(53.0 \%)$ had children. The mean ages of participants living with a person other than their parents or living alone, participants living with their parents, married participants without children and married participants with children were $36.7 \pm 6.5$ years, $37.2 \pm 7.6$ years, $40.5 \pm 5.6$ years and $40.3 \pm 6.1$ years, respectively. There were statistically significant differences in the proportion of current drinkers and frequency of weekly breakfast skipping according to marital and parental status and family members living together. There were no significant differences in other characteristics between unmarried participants and married participants. 
Table1. Characteristics of the participants according to existence of family members living together in this study.

\begin{tabular}{|c|c|c|c|c|c|}
\hline & \multicolumn{2}{|c|}{ Unmarried } & \multicolumn{2}{|c|}{ Married } & \multirow[b]{2}{*}{$\begin{array}{c}p \\
\text { value }\end{array}$} \\
\hline & $\begin{array}{l}\text { Single / Living with a } \\
\text { person other than } \\
\text { their parents }(\mathrm{n}=41)\end{array}$ & $\begin{array}{l}\text { Living with parents } \\
\qquad(\mathrm{n}=58)\end{array}$ & $\begin{array}{l}\text { Without children } \\
\quad(\mathrm{n}=42)\end{array}$ & $\begin{array}{l}\text { With children } \\
\quad(n=159)\end{array}$ & \\
\hline Age (year) & $36.66 \pm 6.50$ & $37.17 \pm 7.56$ & $40.48 \pm 5.63$ & $40.28 \pm 6.14$ & $<0.001$ \\
\hline Male & $17(41.46)$ & $22(37.93)$ & $26(61.90)$ & $85(53.46)$ & 0.052 \\
\hline \multicolumn{6}{|l|}{ Employment status } \\
\hline Regular employment & $27(65.85)$ & $37(63.79)$ & $26(61.90)$ & $94(59.12)$ & 0.753 \\
\hline Part time & $10(24.39)$ & $17(29.31)$ & $9(21.43)$ & $44(27.67)$ & \\
\hline Other & $4(9.76)$ & $4(6.90)$ & $7(16.67)$ & $21(13.21)$ & \\
\hline Working time (hours) & $8.28 \pm 1.11$ & $7.88 \pm 1.73$ & $7.95 \pm 1.66$ & $7.97 \pm 2.07$ & 0.736 \\
\hline Commuting time (hours) & $0.75 \pm 0.49$ & $0.94 \pm 0.73$ & $0.89 \pm 0.46$ & $0.86 \pm 0.58$ & 0.476 \\
\hline Age of youngest child (years) & - & & & $9.20 \pm 5.86$ & - \\
\hline \multicolumn{6}{|l|}{ Self-rated health } \\
\hline Good & $28(68.29)$ & $48(82.76)$ & $33(78.57)$ & $116(72.96)$ & 0.323 \\
\hline Bad & $13(31.71)$ & $10(17.24)$ & $9(21.43)$ & $43(27.04)$ & \\
\hline \multicolumn{6}{|l|}{ Smoking habit } \\
\hline Current smokers & $9(21.95)$ & $5(8.62)$ & $8(19.05)$ & $37(23.27)$ & 0.115 \\
\hline Not current smokers & $32(78.05)$ & $53(91.38)$ & $34(80.95)$ & $122(76.73)$ & \\
\hline \multicolumn{6}{|l|}{ Drinking habit } \\
\hline Current drinkers & $14(34.15)$ & $9(15.52)$ & $9(21.43)$ & $57(35.85)$ & 0.017 \\
\hline Not current drinkers & $27(65.85)$ & $49(84.48)$ & $33(78.57)$ & $102(64.15)$ & \\
\hline Frequency of weekly breakfast skipping (times/week) & $2.08 \pm 2.39$ & $1.73 \pm 2.42$ & $2.17 \pm 2.83$ & $1.20 \pm 2.01$ & 0.025 \\
\hline Frequency of weekly eating out (times/week) & $3.26 \pm 2.73$ & $2.63 \pm 3.00$ & $2.22 \pm 2.08$ & $2.22 \pm 2.61$ & 0.134 \\
\hline Score of dietary variety (score) & $1.34+1.80$ & $2.50 \pm 3.14$ & $1.86 \pm 2.30$ & $1.88 \pm 2.23$ & 0.121 \\
\hline
\end{tabular}

Values are mean \pm standard deviation or number $(\%)$

Associations of marital and parental status and family members living together with self-rated health, smoking habit and drinking habit

Table 2 shows multivariate-adjusted associations of marital and parental status and family members living together with healthrelated behaviors including self-rated health, smoking habit and drinking habit.

After adjustments for age and sex (Model 1), the risks of current drinking in unmarried participants living with their parents significantly decreased comparing to the reference (single/unmarried and living with a person other than their parents). The risks of bad self-rated health and current smoking in unmarried participants living with their parents tended to decrease comparing to the reference, though there was no statistically significant difference. After adjustments for age, sex, employment status and working time (Model 2), the results in Model 2 were similar to those in Model 1 . To assess whether the association of the presence of a partner and/or children in health-related behaviors including selfrated health, smoking habit and drinking habit was confounded, age of youngest child (Model 3) was further adjusted. After adjustment for age of youngest child, the ORs (95\% CIs) for current drinking in unmarried participants living with their parents, married participants without children and married participants with children were $0.35(0.13-0.93 ; p=0.036), 0.40(0.14-1.11 ; p=0.079)$ and $1.10(0.41-2.97 ; p=0.856)$, respectively. There was no significant association between marital and parental status and family members living together and health-related behaviors including selfrated health and smoking habit in Model 3.
Associations of marital and parental status and family members living together with breakfast skipping, takeaway-food consumption and dietary diversity

Table 3 shows multivariate-adjusted means of each of the dietary habits including breakfast skipping, eating out and dietary variety according to marital and parental status and family members living together.

In Model 1, the adjusted means of frequency of weekly breakfast skipping and frequency of eating out showed significant inverse associations with marital and parental status and family members living together ( $p$ for trend $=0.028$ and 0.031 , respectively). Those results in Model 2 were similar to the results in Model 1. However, there was no significant association of marital and parental status and family members living together with frequency of weekly breakfast skipping or frequency of eating out after adjustment for age of youngest child (Model 3). There was no significant association of marital and parental status and family members living together with dietary variety.

\section{DISCUSSION}

In this study, the OR of current drinking in unmarried participants living with their parents was decreased by $65 \%$ compared to the reference. In addition, although the presence of family tended to decrease the frequency of breakfast skipping and the frequency of eating out, there were no significant association between the presence of family and frequency of weekly breakfast skipping or the frequency of eating out after adjustment for age of youngest child. For participants who lived with a partner and children, dietary habits such as skipping breakfast and eating out were greatly influenced by the age of youngest child in our study. On 
Table2. Odd ratios (95\% confidence intervals) for self-rated health, smoking habit and drinking habit according to the existence of family members living together.

\begin{tabular}{|c|c|c|c|c|c|c|c|}
\hline Variables & case/control & $\begin{array}{c}\text { Model } 1 \\
\text { OR }(95 \% \mathrm{CI})\end{array}$ & $\begin{array}{c}p \\
\text { value }\end{array}$ & $\begin{array}{c}\text { Model } 2 \\
\text { OR }(95 \% \mathrm{CI})\end{array}$ & $\begin{array}{c}p \\
\text { value }\end{array}$ & $\begin{array}{c}\text { Model } 3 \\
\text { OR }(95 \% \mathrm{CI})\end{array}$ & $\begin{array}{c}p \\
\text { value }\end{array}$ \\
\hline \multicolumn{8}{|l|}{ Bad self-rated health } \\
\hline $\begin{array}{l}\text { Single / unmarried and living with a } \\
\text { person other than their parents }\end{array}$ & $13 / 28$ & 1.00 (reference) & & 1.00 (reference) & & 1.00 (reference) & \\
\hline Unmarried and living with parents & $10 / 48$ & $0.43(0.17-1.12)$ & 0.084 & $0.42(0.16-1.11)$ & 0.082 & $0.41(0.16-1.08)$ & 0.169 \\
\hline Married without children & $9 / 33$ & $0.52(0.19-1.43)$ & 0.207 & $0.54(0.19-1.50)$ & 0.237 & $0.52(0.19-1.45)$ & 0.173 \\
\hline Married with children & $43 / 116$ & $0.71(0.33-1.52)$ & 0.375 & $0.71(0.32-1.54)$ & 0.381 & $0.94(0.33-2.63)$ & 0.336 \\
\hline \multicolumn{8}{|l|}{ Current smoking } \\
\hline $\begin{array}{l}\text { Single / unmarried and living with a } \\
\text { person other than their parents }\end{array}$ & $9 / 32$ & 1.00 (reference) & & 1.00 (reference) & & 1.00 (reference) & \\
\hline Unmarried and living with parents & $5 / 53$ & $0.33(0.10-1.10)$ & 0.070 & $0.32(0.10-1.08)$ & 0.066 & $0.32(0.10-1.08)$ & 0.066 \\
\hline Married without children & $8 / 34$ & $0.60(0.20-1.82)$ & 0.363 & $0.59(0.19-1.81)$ & 0.356 & $0.57(0.19-1.78)$ & 0.335 \\
\hline Married with children & $37 / 122$ & $0.85(0.36-2.04)$ & 0.721 & $0.85(0.35-2.03)$ & 0.712 & $1.71(0.56-5.21)$ & 0.345 \\
\hline \multicolumn{8}{|l|}{ Current drinking } \\
\hline $\begin{array}{l}\text { Single / unmarried and living with a } \\
\text { person other than their parents }\end{array}$ & $14 / 27$ & 1.00 (reference) & & $1.00($ reference $)$ & & 1.00 (reference) & \\
\hline Unmarried and living with parents & $9 / 49$ & $0.35(0.13-0.92)$ & 0.033 & $0.34(0.13-0.92)$ & 0.033 & $0.35(0.13-0.93)$ & 0.036 \\
\hline Married without children & $9 / 33$ & $0.38(0.14-1.06)$ & 0.065 & $0.39(0.14-1.08)$ & 0.069 & $0.40(0.14-1.11)$ & 0.079 \\
\hline Married with children & $57 / 102$ & $0.87(0.41-1.85)$ & 0.711 & $0.87(0.41-1.86)$ & 0.716 & $1.10(0.41-2.97)$ & 0.856 \\
\hline
\end{tabular}

Wald confidence intervals for adjusted ORs (95\% CIs)

Model 1 : adjusted for age (continuous) and sex (binary : men and women)

Model 2 : adjusted for Model $1+$ employment status (categorical : regular employment, part time or other) and working time (continuous)

Model 3 : adjusted for Model 2 + age of youngest child (as continuous : no child, 0-4 years, 5-9 years, 10-14 years, 15-19 years, $\geq 20$ years)

Abbreviations : odds ratios, OR: confidence intervals, $\mathrm{CI}$

Table3. Multivariate-adjusted means (95\% confidence intervals) for breakfast skipping, eating out and dietary variety according to the existence of family members living together.

\begin{tabular}{|c|c|c|c|c|}
\hline Variables & Subject & $\begin{array}{l}\text { Model } 1 \\
\text { Adjusted mean }(95 \% \mathrm{CD})\end{array}$ & $\begin{array}{l}\text { Model } 2 \\
\text { Adjusted mean } 95 \% \mathrm{C}\end{array}$ & $\begin{array}{c}\text { Model } 3 \\
\text { Adjusted mean }(95 \% \mathrm{CD})\end{array}$ \\
\hline
\end{tabular}

Weekly breakfast skipping (times/week)

Single / unmarried and living with a person other than their 41 parents

Unmarried and living with parents

$41 \quad 2.02(1.32-2.73)$

58

42

Married without children

Married with children

$p$ for trend

Weekly eating out (times/week)

Single / unmarried and living with a person other than their 41 parents

Unmarried and living with parents

Married without children

Married with children

$p$ for trend

Dietary variety (score)

Single / unmarried and living with a person other than their 41 parents

Unmarried and living with parents

Married without children

Married with children

$p$ for trend

Values are adjusted mean $(95 \% \mathrm{CI})$

Model 1 : adjusted for age (continuous) and sex (binary : men and women)

Model $2:$ adjusted for Model $1+$ employment status (categorical : regular employment, part time or other) and working time (continuous)

Model 3 : adjusted for Model 2 + age of youngest child (as continuous : no child, $0-4$ years, $5-9$ years, 10-14 years, $15-19$ years, $\geq 20$ years)

Abbreviations : confidence intervals, CI 
the other hand, there were no significant associations of the presence of family members with three health-related habits including bad self-rated health, smoking habit and diet variety in this study.

Our results showed that current drinking in unmarried participants living with their parents was significantly decreased compared to that in single participants, though there was no association between the presence of partner and children and drinking habit. Previous studies suggested that alcohol consumption status was associated with family structure and/or family composition (23-26). Those studies showed that the amount of alcohol consumption was dependent on whether their parents drink alcohol or not. The presence of one parent and especially both parents influences the amount of alcohol intake. It has been reported that the percentage of persons abstaining from alcohol is lower in persons living with their parents than in persons not living with their parents. This might be the reason for the risk of current drinking in unmarried participants living with their parents being lower than that in single participants (Table 2). However, since we could not obtain data about alcohol consumption by parents in this study, we could not perform analysis with consideration of alcohol consumption by parents. Changes in life-stages such as partnering and/or parenting have been reported to change lifestyle and/or behavior such as alcohol consumption (5-8). Therefore, though we expected that married participants would have a lower frequency of current drinking than that of single participants, there was no difference in the present study. One reason for this result may be the difference in the definition of drinking. In this study, we defined participants with a drinking frequency of more than one time a week as current drinkers, because we wanted to assess a drinking habit. On the other hand, previous studies used excessive alcohol consumption patterns such as alcohol abuse for analysis $(23,24)$.

It has reported that both the status of partnering and that of parenting are related to dietary behavior such as skipping breakfast and eating out. Several studies conducted in Western countries suggested that both partnering and parenting are associated with a lower risk of skipping breakfast $(13,14,18)$. Similar results were also obtained in studies conducted in Asian countries including Japan $(20,21)$. In our study, the presence of a partner and children tended to decrease the frequency of breakfast skipping and eating out after adjustment for age, sex, employment status and working time. Participants with a partner and/or children might be more likely to eat breakfast than those without a partner and/or children because they have a morning routine of making breakfast for their partner and/or children. However, there was no significant association of the presence of a partner and children with frequency of breakfast skipping or frequency of eating out after further adjustment for age of youngest child in this study. One reason for this result may be that the age of youngest child rather than the presence of a partner and/or children plays a greater role in predicting dietary habits such as breakfast skipping and eating out. To determine whether age of the youngest child is associated with dietary habits, we estimated the standardized coefficients $(\beta)$ for each of the dietary habits according to a 1-unit increase in age of the youngest childin subanalysis after controlling for age, sex, employment status, and working time among persons living with their partner and children. Significant associations were observed between age of the youngest child and frequency of eating out $(\beta=-$ $0.254, p=0.009$ ). Although the association did not reach statistical significance, age of the youngest child was negatively associated with frequency of breakfast skipping $(\beta=-0.130, p=0.187)$. This means that an increase in the age of the youngest child might affect dietary behaviors including breakfast skipping and eating out. Hirasawa et al. also reported that participants who answered 'eat until full' and 'eat an unbalanced diet' tended to be taking care of younger children than participants with other answers (21). Thus, not only the presence of children but also the age of children might be an important factor when assessing the association between the status of partnering and parenting and dietary habits.

Our study has some limitations that need to be taken into account when interpreting the results. First, there is a possibility that a sample error occurred because we conducted an Internet panel survey. It has been reported that biased age of subjects in an Internet survey is biased toward a relatively young population aged 20-40 years (27) depending on the age of the usual group (20-40 years) of Internet users (28). In addition, it has been reported that sample errors occur because the Internet survey target is Internet users and voluntary investigation participants (29). Thus, it is necessary to interpret the results after taking into account the presence of a sampling error. Second, because of the cross-sectional approach, the temporal relationship between the presence of a partner and/or children and dietary habits remains obscure. Third, the sample size of this study was small. In addition, the findings might not be generalizable to other populations because the study participants were only young Japanese workers. Fourth, the association between drinking habits and family structure might be underestimated because current drinkers in this study had a wide range of drinking frequencies. Therefore, to determine whether the association between drinking habits and family composition changes depending on the definition of current drinking, we estimated the ORs and 95\% CIs for current drinking according to family composition in a subanalysis after controlling for covariates. As a result, the ORs $(95 \% \mathrm{CIs})$ for current drinking (e.g., more over 3 times a week) in unmarried participants living with their parents, married participants without children and married participants with children were $0.27(0.09-0.84 ; p=0.023), 0.23(0.07$ $0.78 ; p=0.018)$ and $0.45(0.14-1.46 ; p=0.183)$, respectively. Those associations were the same in the case of drinking frequency of more over 1 time a week (Table 2). Although the frequency of drinking (e.g., more than 5 times a week) did not reach statistical significance, those associations were similar to the case of drinking frequency of more over 1 time a week (Table 2). Thus, the association between family composition and current drinking might be similar regardless of the definition of current drinking (e.g., more than one time, three times or five times a week). Fifth, we could not obtain data for factors associated with drinking behavior. Some previous studies showed that biological factors (e.g., genetic polymorphism of alcohol-metabolizing enzymes), cultural factors (e.g., religion) and/or psychological factors (e.g., alcohol outcome expectancy) were factors influencing drinking behavior including the amount of alcohol intake and frequency of drinking (30-32). Therefore, those points must be taken into account when interpreting the present association of marital and parental status and family members living together with drinking habit. Sixth, almost all of the data obtained were based on self-reporting, and there is a possibility that the association between partnering and parenting and dietary habits may be underestimated by misclassification of data. Finally, there may be confounding factors that were not removed completely, though some potentially important confounders were adjusted in the analysis.

In conclusion, it is possible that the presence of parents living together affects current drinking in Japanese workers. In addition, the age of children might affect the frequency of breakfast skipping and frequency of eating out for Japanese workers who live with a partner and children. A further large-scale prospective study on the effects of partnering and/or parenting on health-related behaviors including dietary habits is needed.

\section{CONFLICT OF INTEREST}

All authors state that they have no conflicts of interest. 


\section{ABBREVIATIONS USED}

$\mathrm{OR}$, odds ratio ; CI, confidence intervals

\section{ACKNOWLEDGEMENTS}

This research was supported in part by Grants-in-Aid for food education promotion project (2015) from Tokushima Prefecture (MN) (http : //www.pref. tokushima.jp/) and by Grants-in Aid for Young Scientists (B) (15K16228) from the Ministry of Education, Culture, Sports, Science and Technology of Japan (MN). The funders/sponsors had no role in the design, conduct, or reporting of the study or in the decision to submit the manuscript for publication.

The authors thank the study participants for completing this study.

\section{REFERENCE LIST}

1. National Institute of Population and Social Security Research : LATEST DEMOGRAPHIC STATISTICS 2011. Population Research Series no. 324. Japan : National Institute of Population and Social Security Research, 2011 http : //www.ipss.go.jp/ syoushika/bunken/data/pdf/206338.pdf (in Japanese) (accessed December 2016)

2. Ministry of Health, Labour and Welfare in Japan: Vital Statistics: Trends in mean age of mother by live birth order: Japan. Japan : Ministry of Health, Labour and Welfare, 2015

3. Ball K, Jeffery RW, Abbott G, McNaughton SA, Crawford D : Is healthy behavior contagious : associations of social norms with physical activity and healthy eating. Int J Behav Nutr Phys Act $7: 86,2010$

4. Berge JM, MacLehose R, Eisenberg ME, Laska MN, Neumark-Sztainer D : How significant is the 'significant other'? Associations between significant others' health behaviors and attitudes and young adults' health outcomes. Int $J$ Behav Nutr Phys Act 9: 35, 2012

5. Umberson D : Family status and health behaviors : social control as a dimension of social integration. J Health Soc Behav 28 : 306-319, 1987

6. Wood RG, Goesling B, Avellar S : The Effects of Marriage on Health: A Synthesis of Recent Research Evidence, 2007 https : //aspe.hhs.gov/basic-report/effects-marriage-healthsynthesis-research-evidence (accessed September 2018)

7. Koball HL, Moiduddin E, Henderson J, Goesling B, Besculides $\mathrm{M}$ : What Do We Know About the Link Between Marriage and Health? J Fam Issues 31 : 1019-1040, 2010

8. Fu H, Goldman $\mathrm{N}$ : Incorporating health into models of marriage choice: Demographic and sociological perspectives. JMarriage Fam 58:740-758, 1996

9. Berkman JF, Glass T: Social integration, social networks, social support, and health. In : Berkman LF, Kawachi I, eds. Social epidemiology. Oxford University Press, New York, 2000, pp. 137-173

10. Shaikh AR, Yaroch AL, Nebeling L, Yeh MC, Resnicow K: Psychosocial predictors of fruit and vegetable consumption in adults a review of the literature. Am J Prev Med 34 : 535-543, 2008

11. McNeill LH, Kreuter MW, Subramanian SV : Social environment and physical activity : a review of concepts and evidence. Soc sci Med $63: 1011-1022,2006$

12. Worsley A : Cohabitation-gender effects on food consumption. In J Biosoc Res 10 : 107-122, 1988

13. Smith KJ, Gall SL, McNaughton SA, Blizzard L, Dwyer T,
Venn AJ : Skipping breakfast : longitudinal associations with cardiometabolic risk factors in the Childhood Determinants of Adult Health Study. Am J Clin Nutr $92: 1316$-1325, 2010

14. Berge JM, Bauer KW, Maclehose R, Eisenberg ME, NeumarkSztainer D : Associations between relationship status and dayto-day health behaviors and weight among diverse young adults. Fam Syst Health 32 : 67-77, 2014

15. Elstgeest LE, Mishra GD, Dobson AJ : Transitions in living arrangements are associated with changes in dietary patterns in young women. J Nutr 142 : 1561-1567, 2012

16. Olson $\mathrm{CM}$ : Tracking of food choices across the transition to motherhood. J Nutr Educ Behav 37 : 129-136, 2005

17. Laroche HH, Wallace RB, Snetselaar L, Hillis SL, Steffen LM : Changes in diet behavior when adults become parents. J Acad Nutr Diet 112 : 832-839, 2012

18. Smith KJ, McNaughton SA, Gall SL, Otahal P, Dwyer T, Venn $\mathrm{AJ}$ : Associations between Partnering and Parenting Transitions and Dietary Habits in Young Adults. J Acad Nutr Diet 117 : 1210-1221, 2017

19. Berge JM, Larson N, Bauer KW, Neumark-Sztainer D : Are parents of young children practicing healthy nutrition and physical activity behaviors? Pediatrics $127: 881-887,2011$

20. Nishimura M, Takemori K, Yamamoto $\mathrm{H}$ : Life events and lifestyle habits of women in their $20 \mathrm{~s}$ and $30 \mathrm{~s}$. Japanese Journal of Public Health 55 : 503-510, 2008 (in Japanese)

21. Hirasawa Y, Ohyama Y, Araki Y, Fuji N, Wakabayashi C, Yoshinaka Y, Fukuda R, Tanaka N : Survey of the dietary habits of working women : relationship with the presence and age of children. Japanese Journal of Occupational Medicine and Traumatology $62: 399-403,2014$ (in Japanese)

22. Kumagai S, Watanabe S, Shibata H, Amano H, Fujiwara Y, Shinkai S, Yoshida H, Suzuki T, Yukawa H, Yasumura S, Haga $\mathrm{H}$ : Effects of dietary variety on declines in high-level functional capacity in elderly people living in a community. Japanese Journal of Public Health 50: 1117-1124, 2003 (in Japanese)

23. RüütelE, Sisask M, Värnik A, Värnik P, Carli V, Wasserman C, Hoven CW, Sarchiapone M, Apter A, Balazs J, Bobes J, Brunner R, Corcoran P, Cosman D, Haring C, losue M, Kaess M, Kahn JP, Pośtuvan V, Sáiz PA, Wasserman D : Alcohol consumption patterns among adolescents are related to family structure and exposure to drunkenness within the family : results from the SEYLE project. Int J Environ Res Public Health $11: 12700-12715,2014$

24. Chen CH, Chang YC, Hsieh YH, Chen YC, Huang YC, Kuo HW : The association between drinking habits and family relationships in 3 villages of indigenous Taiwanese. Asia Pac J Public Health. 27 : NP2721-2731, 2015

25. Isohanni M, Oja H, Moilanen I, Koiranen M : Teenage alcohol drinking and non-standard family background. Soc Sci Med $38: 1565-1574,1994$

26. Persson E, Hanson BS, Rastam AS : Alcohol habits among teenagers in Sweden : factors of importance. J Stud Alcohol $55: 719-725,1994$

27. Bell DS, Kahn CE : Health status assessment via the World Wide Web. Proc AMIA Annu Fall Symp : 338-342, 1996

28. Ministry of Internal Affairs and Communications: WHITE PAPER Information and Communications in Japan Year 2015, 2015 http : //www.soumu.go.jp/johotsusintokei/whitepaper/ eng/WP2015/chapter-2.pdf (accessed December 2016)

29. Eysenbach $\mathrm{G}$, Wyatt $\mathrm{J}$ : Using the Internet for surveys and health research. J Med Internet Res 4 : E13, 2002

30. Harada $\mathrm{S}$ : Genetic polymorphism of alcohol metabolizing enzymes and its implication to human ecology. J Anthrop Soc Nippon $99: 123-139,1991$

31. Leigh BC : In search of the Seven Dwarves : issues of measurement and meaning in alcohol expectancy research. Psychol 
Bull $105: 361-373,1989$

32. Grube JW, Morgan $\mathrm{M}$ : Attitude-social support interactions : Contingent consistency effects in the prediction of adolescent smoking, drinking, and drug use. Soc Psychol Q 53 : 329-339, 1990 